\title{
PENGARUH MASSA RAGI DAN WAKTU FERMENTASI TERHADAP BIOETANOL DARI BIJI DURIAN
}

\author{
Farida Hanum, Nurhasmawaty Pohan, Mulia Rambe, Ratih Primadony*, Mei Ulyana \\ Departemen Teknik Kimia, Fakultas Teknik Universitas Sumatera Utara, Medan \\ Jalan Almamater Kampus USU Medan 20155, Indonesia \\ *E-mail: ratihsipayung@gmail.com
}

\begin{abstract}
Abstrak
Bioetanol merupakan etanol yang terbuat dari tanaman yang mengandung pati, gula, dan tanaman berselulosa lainnya. Penelitian ini menggunakan biji durian yang mengandung karbohidrat dan gula yang cukup tinggi sebagai bahan baku dan bertujuan untuk membuat bioetanol dari biji durian dengan variasi massa ragi yang ditambahkan dan waktu fermentasi. Variabel yang digunakan adalah perubahan massa ragi 3\%; 6\%; dan 9\%, pH fermentasi 4,5 dan waktu fermentasi 0; 24; 48; 72; dan 96 jam. Dari analisis yang dilakukan diperoleh hasil kadar bioetanol yang tertinggi sebesar 18,9988\% pada massa ragi $6 \%$ dan waktu fermentasi 48 jam.
\end{abstract}

Kata Kunci : bioetanol, asam klorida, biji durian

\begin{abstract}
Bioethanol is the ethanol made from plants that contains starch, sugar, and the others cellulose plants. This study uses durian seeds that contain carbohydrate and sugar as basic material and the purpose is to make bioethanol from durian seeds with the variation of yeast mass added and fermentation time. The variables used were the changes of yeast mass 3\%; 6\%; and 9\%, fermentation $\mathrm{pH}$ was 4,5, and fermentation times were 0; 24; 48; 72; and 96 hours. The results of experiment were the bioethanol concentration was $18.9988 \%$ at the yeast mass $6 \%$ with 48 hour for the fermentation.
\end{abstract}

Keywords : ethanol, hydrochloric acid, durian seeds

\section{Pendahuluan}

Ketersediaan energi merupakan syarat mutlak khususnya dalam pelaksanaan pembangunan nasional baik pada saat ini maupun masa yang akan datang, guna menjamin pemenuhan pasokan energi yang merupakan tantangan utama bagi bangsa Indonesia. Kebutuhan energi umumnya didominasi oleh energi fosil seperti minyak bumi, gas bumi dan batu bara. Sumber energi fosil ini merupakan sumber energi yang terbatas yang memerlukan antisipasi untuk mengurangi ketergantungan terhadap energi tersebut [15].

Salah satu alternatif pengganti bahan bakar fosil adalah dengan bioenergi seperti bioetanol. Bioetanol adalah bahan bakar nabati yang tak pernah habis selama mentari masih memancarkan sinarnya, air tersedia, oksigen berlimpah dan kita mau melakukan budidaya pertanian. Sumber bioetanol dapat berupa singkong, ubi jalar, tebu, jagung, sorgum biji, sorgum manis, sagu, aren, nipah, lontar, kelapa dan padi [10].

\section{Teori}

Durian (Durio zibethinus) merupakan tanaman buah berupa pohon Sebutan durian diduga berasal dari istilah Melayu yaitu dari kata duri yang diberi akhiran -an sehingga menjadi durian [8]. Biji durian (pongge) memiliki kandungan pati yang cukup tinggi sehingga dapat digunakan sebagai pengganti bahan makanan dan dapat dimanfaatkan sebagai bioetanol [1].

Alkohol (khususnya etanol) dapat dibuat dari berbagai bahan hasil pertanian. Secara umum bahan- bahan tersebut dapat dibagi dalam tiga golongan yaitu:

1) Bahan yang mengandung turunan gula (molases, gula tebu, gula bit, sari buah anggur, dan sari buah lainnya),

2) Bahan-bahan yang mengandung pati biji-bijian, kentang, dan tapioka), dan

3) Bahan yang mengandung selulosa (kayu, dan beberapa limbah pertanian lainnya).

Selain dari ketiga jenis bahan tersebut diatas etanol juga dapat dibuat dari bahan bukan dari hasil pertanian tetapi dari bahan yang merupakan hasil proses lain. Sebagai contohnya adalah etilen. Bahanbahan yang mengandung monosakarida langsung dapat difermentasi, akan tetapi disakarida, pati maupun karbohidrat kompleks harus dihidrolisis terlebih dahulu menjadi komponen yang sederhana yaitu monosakarida [4].

Bahan-bahan tersebut diatas harus mengalami perlakuan pendahuluan sebelum masuk kedalam proses fermentasi agar proses tersebut berjalan dengan optimal. Disakarida (seperti gula pasir) harus dihidrolisis menjadi glukosa dan fruktosa. Terbentuknya glukosa dan monosakarida yang lain menunjukkan bahwa proses pendahuluan telah berakhir dan bahan selanjutnya telah siap difermentasi. Secara kimiawi reaksi dalam proses fermentasi berjalan cukup panjang, karena terjadi suatu deret reaksi yang masing-masing dipengaruhi oleh enzim khusus [4].

Seperti diketahui, etanol dikategorikan dalam dua kelompok utama : 
1) Etanol $95-96 \% \mathrm{v} / \mathrm{v}$, disebut "etanol hidrat" yang dibagi dalam :

- Technical/raw spit grade, digunakan untuk bahan bakar spirtus, minuman, desinfektan dan pelarut

- Industrial grade, digunakan untuk bahan baku industri pelarut

- Potable grade, untuk minuman berkualitas tinggi.

2) Etanol > $99.5 \% \mathrm{v} / \mathrm{v}$, digunakan untuk bahan bakar. Jika dimurnikan lebih lanjut dapat digunakan untuk keperluan farmasi dan pelarut di laboratorium analisis. Etanol ini disebut fuel grade thanol (FGE) atau anhydrous ethanol (etanol anhidrat) atau etanol kering, yakni etanol yang bebas air atau hanya mengandung air minimal.

Etanol memiliki banyak manfaat bagi masyarakat karena memiliki sifat yang tidak beracun. Selain itu, etanol juga memiliki banyak sifat-sifat, baik secara fisika maupun kimia. Adapun sifat-sifat fisika etanol dapat dilihat pada tabel 1 .

Tabel 1. Sifat-Sifat Fisika Etanol [9]

\begin{tabular}{|l|l|}
\hline $\begin{array}{l}\text { Sifat-Sifat Fisika } \\
\text { Etanol }\end{array}$ & \multicolumn{1}{|c|}{ Keterangan } \\
\hline Berat Molekul & $46,07 \mathrm{gr} / \mathrm{grmol}$ \\
Titik Lebur & $-112^{\circ} \mathrm{C}$ \\
Titik didih & $78,4^{\circ} \mathrm{C}$ \\
Densitas & $0,7893 \mathrm{gr} / \mathrm{ml}$ \\
Indeks bias & $1,36143 \mathrm{cP}$ \\
Viskositas $20^{\circ} \mathrm{C}$ & $1,17 \mathrm{cP}$ \\
Panas penguapan & $200,6 \mathrm{kal} / \mathrm{gr}$ \\
Warna Cairan & tidak berwarna \\
Kelarutan & larut dalam air dan eter \\
Aroma & memiliki aroma yang khas \\
\hline
\end{tabular}

Etanol dimanfaatkan untuk berbagai keperluan, antara lain:

1) Bahan baku industri atau senyawa kimia, contoh: industri minuman beralkohol, industri asam asetat dan asetaldehid.

2) Pelarut dalam industri, contoh: industri farmasi, kosmetika dan plastik.

3) Bahan desinfektan, contoh: peralatan kedokteran, rumah tangga dan peralatan di rumah sakit.

4) Bahan baku motor.

Etanol atau etil alkohol yang di pasaran lebih dikenal sebagai alkohol merupakan senyawa organik dengan rumus kimia $\mathrm{C}_{2} \mathrm{H}_{5} \mathrm{OH}$. Dalam kondisi kamar, etanol berwujud cairan yang tidak berwarna, mudah menguap, mudah terbakar, mudah larut dalam air dan tembus cahaya. Etanol adalah senyawa organik golongan alkohol primer. Sifat fisik dan kimia etanol bergantung pada gugus hidroksil. Faktorfaktor yang dapat mempengaruhi jumlah etanol yang dihasilkan dari fermentasi adalah mikroorganisme dan media yang digunakan, adanya komponen media yang dapat menghambat pertumbuhan serta kemampuan fermentasi mikroorganisme dan kondisi selama fermentasi. Selain itu, hal-hal yang perlu diperhatikan selama fermentasi adalah pemilihan khamir, konsentrasi gula, keasaman, ada tidaknya oksigen dan suhu dari perasan buah. Pemilihan sel khamir didasarkan pada jenis karbohidrat yang digunakan sebagai medium untuk memproduksi alkohol dari pati dan gula digunakan Saccharomyces cerevisiae. Proses fermentasi sama dengan $\mathrm{pH}$ optimum untuk proses pertumbuhan khamir yaitu $\mathrm{pH}$ 4,0-4,5. Etanol dihasilkan dari gula yang merupakan hasil aktivitas fermentasi sel khamir. Khamir yang baik digunakan untuk menghasilkan etanol adalah dari genus Saccharomyces. Kriteria pemilihan khamir untuk produksi etanol adalah mempunyai laju fermentasi dan laju pertumbuhan cepat, perolehan etanol banyak, tahan terhadap konsentrasi etanol dan glukosa tinggi, tahan terhadap konsentrasi garam tinggi, $\mathrm{pH}$ optimum serta fermentasi rendah, temperatur optimum fermentasi sekitar 25-30 tahan terhadap stress fisika dan kimia [2].

\section{Metodologi Penelitian}

Pembuatan Tepung Biji Durian

1. Sebanyak $10 \mathrm{~kg}$ biji durian dicuci bersih.

2. Biji durian dibersihkan dari kulit arinya yang berwarna cokelat.

3. Biji durian dicuci bersih.

4. Diiris dengan ketebalan 2-3 mm

5. Lendir dari biji durian yang telah diirisi dihilangkan dengan cara menambahkan garam pada biji durian, dicampur, diaduk-aduk dibawah air mengalir sampai keluar busa.

6. Direndam dengan air kapur selama 1 jam.

7. Ditiriskan lalu dicuci dengan air mengalir sampai lendir berkurang dan ditiriskan.

8. Dijemur di bawah sinar matahari.

9. Hasil pengeringan kemmudian dihaluskan dengan mesin pengiling dan diayak dengan ayakan 50 mesh hinga diperoleh tepung biji durian[11].

\section{Tahap Pesiapan Bahan Fermentasi}

1. Ditimbang sebanyak 100 gr tepung biji durian

2. Dimasukkan ke dalam beker gelas ukuran 500 $\mathrm{ml}$

3. Ditambahkan aquadest sebanyak $250 \mathrm{ml}$

4. Ditambahkan $\mathrm{HCl} 0,5 \mathrm{M}$ sampai $\mathrm{pH} \mathrm{2,3}$

5. Campuran dipanaskan di dalam panci pengukus sambil diaduk-aduk selama 30 menit pada suhu 93-95 ${ }^{\circ} \mathrm{C}[11]$.

\section{Tahap Fermentasi}

1. Campuran didinginkan pada suhu kamar. 
2. Didinginkan dan disaring hingga tidak ada ampas dalam larutan hasil hidrolisis.

3. Ditambahkan larutan Natrium hidroksida $(\mathrm{NaOH})$ atau asam klorida hingga $\mathrm{pH}$ campuran bahan sampai pada 4,5.

4. Ditambahkan ragi Saccharomyces cerevisiae masing-masing sebanyak $3 \%$ dari berat bahan.

5. Campuran diaduk rata, kemudian ditutup dalam wadah fermentasi.

6. Campuran disimpan dan dibiarkan pada temperatur kaamr dengan waktu 48 jam, 72 jam, dan 96 jam.

7. Dengan menggunakan $\mathrm{pHmeter,} \mathrm{setiap} \mathrm{hari} \mathrm{pH}$ bahan dikontrol sehinggan tetap pada $\mathrm{pH} 4,5$ (jika $\mathrm{pH}$ menurun ditambahkan larutan $\mathrm{NaOH}$ ).

8. Prosedur diulangi untuk perlakuan massa ragi $6 \%$ dan $9 \%$ dari massa bahan[11].

\section{Tahap Destilasi}

1. Peralatan destilasi dirangkai kemudian hasil fermentasi dimasukkan ke dalam labu leher tiga.

2. Ditambahkan $50 \mathrm{ml}$ aquadest lalu di aduk rata.

3. Larutan dipanaskan hingga suhu mencapai $80^{\circ} \mathrm{C}$

4. Destilat ditampung dan diukur volumenya[14].

\section{Prosedur Analisa}

a. Penentuan Jumlah Bioetanol ( $\mathrm{ml})$

1. Destilat hasil destilasi yang ditampung (bioetanol) diukur dengan meggunakan gelas ukur.

2. Volume dicatat untuk tiap-tiap perlakuan [11].

b. Analisis Densitas Bioetanol ( $\mathrm{gr} / \mathrm{ml})$

1. Piknometer diisi dengan bioetanol hasil destilasi dan ditimbang massanya.

2. Selisih massa antara piknometer kosong dan yang berisi bioetanol merupakan massa bioetanol.

3. Densitas bioetanol diperoleh dengan membagi massa bioetanol dengan volumenya.

4. Dicatat densitas yang diperoleh pada tiap-tiap perlakuan [11].

\section{c. Analisis Spesific Grafity (sg) dan API}

Grafity $(G)$

1. Densitas bioetanol telah ditentukan pada prosedur sebelumnya.

2. Dihitung nilai Spesific Grafity untuk masingmasing sampel dengan menggunakan persamaan berikut:

$$
s g=\frac{\text { densitas sampel }\left(\frac{\mathrm{kg}}{\mathrm{m}^{3}}\right)}{\text { densitas air }\left(\frac{\mathrm{kg}}{\mathrm{m}^{3}}\right)}
$$

3. Dihitung nilai API grafity untuk masingmasing sampel dengan persamaan sebagai berikut :

$$
G=\frac{141,5}{s g}-131,5
$$

4. Lalu dicatat semua harga spesific grafity dan API grafity untuk tiap-tiap perlakuan [11].

d. Analisis Nilai Kalor (NK)

1. Nilai kalor dihitung dengan menggunakan persamaan 3.

$$
N K=\frac{2,2046226}{3,9673727} x(18,650+40 x(G-10) \mathrm{kkal} / \mathrm{kg}) \cdots(3)
$$

2. Dicatat semua nilai kalor yang diperoleh untuk tiap-tiap perlakuan [11].

e. Analisis Kadar Bioetanol dengan Metode Berat Jenis

Nilai densitas yang diperoleh sebelumnya di cocokkan pada tabel 2 [9]. Kadar etanol dihitung dengan menginterpolasi data densitas dan kadar etanol.

Tabel 2. Konversi Berat Jenis - Kadar Etanol

\begin{tabular}{|c|c|c|c|}
\hline $\begin{array}{c}\text { Kadar } \\
\text { Etanol }\end{array}$ & $\begin{array}{c}\text { Berat Jenis } \\
\text { Larutan } \\
\text { Etanol (Pada } \\
\text { suhu 30 } \mathbf{~ C )}\end{array}$ & $\begin{array}{c}\text { Kadar } \\
\text { Etanol }\end{array}$ & $\begin{array}{c}\text { Berat Jenis } \\
\text { Larutan } \\
\text { Etanol }\end{array}$ \\
\hline 0 & 0,99568 & 25 & 0,95607 \\
\hline 1 & 0,99379 & 26 & 0,95442 \\
\hline 2 & 0,99194 & 27 & 0,95272 \\
\hline 3 & 0,99014 & 28 & 0,95098 \\
\hline 4 & 0,98839 & 29 & 0,94922 \\
\hline 5 & 0,98670 & 30 & 0,94741 \\
\hline 6 & 0,98507 & 31 & 0,94557 \\
\hline 7 & 0,98347 & 32 & 0,94370 \\
\hline 8 & 0,98189 & 33 & 0,94180 \\
\hline 9 & 0,98031 & 34 & 0,93986 \\
\hline 10 & 0,97875 & 35 & 0,93790 \\
\hline 11 & 0,97723 & 36 & 0,93591 \\
\hline 12 & 0,97573 & 37 & 0,93390 \\
\hline 13 & 0,97424 & 38 & 0,93186 \\
\hline 14 & 0,97278 & 39 & 0,92979 \\
\hline 15 & 0,97133 & 40 & 0,92770 \\
\hline 16 & 0,96990 & 41 & 0,92558 \\
\hline 17 & 0,96844 & 42 & 0,92344 \\
\hline 18 & 0,96697 & 43 & 0,92128 \\
\hline 19 & 0,96547 & 44 & 0,91910 \\
\hline 20 & 0,96395 & 45 & 0,91692 \\
\hline 21 & 0,96242 & 46 & 0,91472 \\
\hline 22 & 0,96087 & 47 & 0,91250 \\
\hline 23 & 0,95929 & 48 & 0,91028 \\
\hline 24 & 0,95769 & 49 & 0,90805 \\
\hline & & & \\
\hline
\end{tabular}

\section{Hasil dan Pembahasan}




\section{Pengaruh Massa Ragi Dan Waktu Fermentasi Terhadap Jumlah Bioetanol}

Dari gambar 1 terlihat bahwa volume bioetanol yang paling banyak dihasilkan pada waktu 48 jam dengan massa ragi $6 \%$ yaitu $3,7 \mathrm{ml}$ kemudian pada waktu 72 jam sebanyak 3,3 ml dan pada waktu 96 jam sebanyak 3,3 ml. Dari grafik diatas dapat diketahui semakin lama waktu fermentasi, volume bioetanol akan semakin meningkat sampai batas waktu tertentu dan kemudian menurun. Hal ini telah sesuai dengan teori dimana semakin lama waktu fermentasi maka volume bioetanol yang dihasilkan semakin banyak. Tetapi pada waktu 72 jam dan 96 jam terjadi penurunan, hal ini disebabkan pada waktu 72 jam dan 96 jam bakteri ( Saccharomyces Cerevisiae) mengalami fase pertumbuhan diperlambat dan mengalami fase kematian sehingga aktivitas bakteri untuk mengubah glukosa semakin menurun [12]. Selain itu, bioetanol yang dihasilkan telah diubah menjadi asam asetat oleh bakteri tersebut sehingga volume bioetanol yang dihasilkan mengalami penurunan.

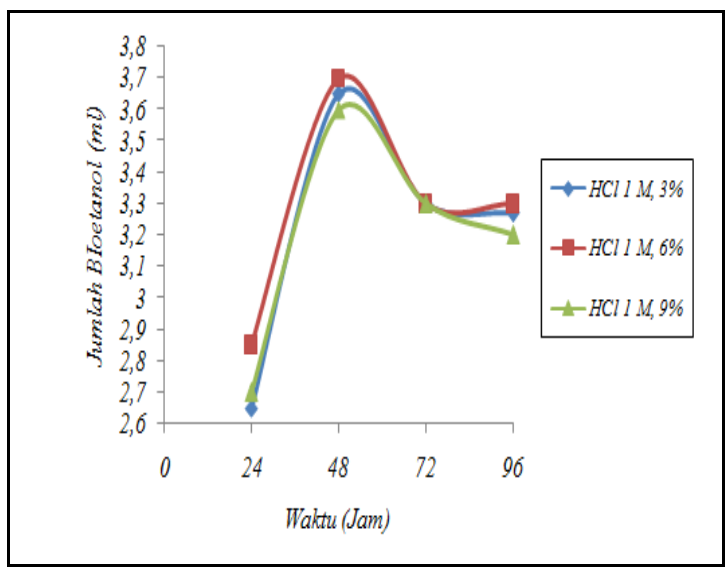

Gambar 1. Pengaruh Massa Ragi dan Waktu Fermentasi Terhadap Jumlah Bioetanol

\section{Pengaruh Massa Ragi Dan Waktu Fermentasi Terhadap Densitas Bioetanol}

Dari gambar 2 terlihat bahwa densitas bioetanol diperoleh 0,966 gr/ml dimana densitas tersebut melebihi dari densitas bioetanol absolut yaitu sebesar 0,789 gr/ml [3]. Hal ini menunjukkan bahwa etanol yang dihasilkan masih belum murni karena bercampur dengan air. Hal ini disebabkan oleh distilasi yang dilakukan hanya distilasi sederhana bukan distilasi azeotrop serta kurang telitinya dalam menjaga kestabilan temperatur distilasi sehingga uap yang keluar bukan hanya bioetanol melainkan bercampur dengan air.

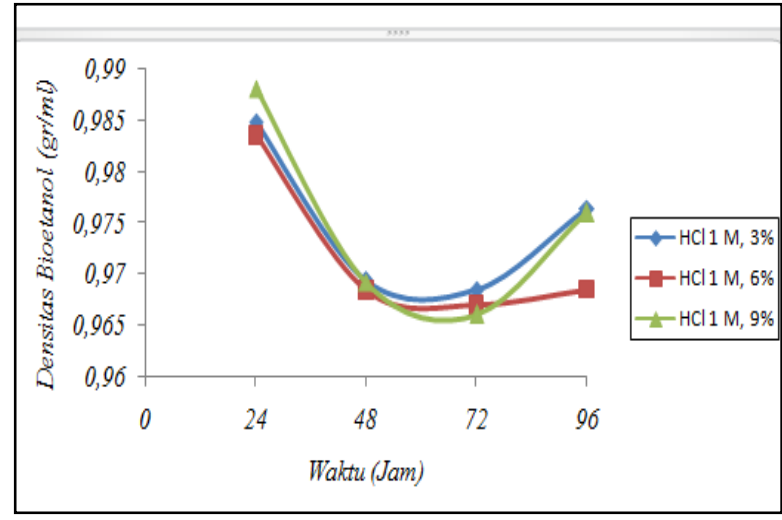

Gambar 2. Pengaruh Massa Ragi dan Waktu Fermentasi Terhadap Densitas Bioetanol

\section{Pengaruh Massa Ragi Dan Waktu Fermentasi} Terhadap Kadar Bioetanol

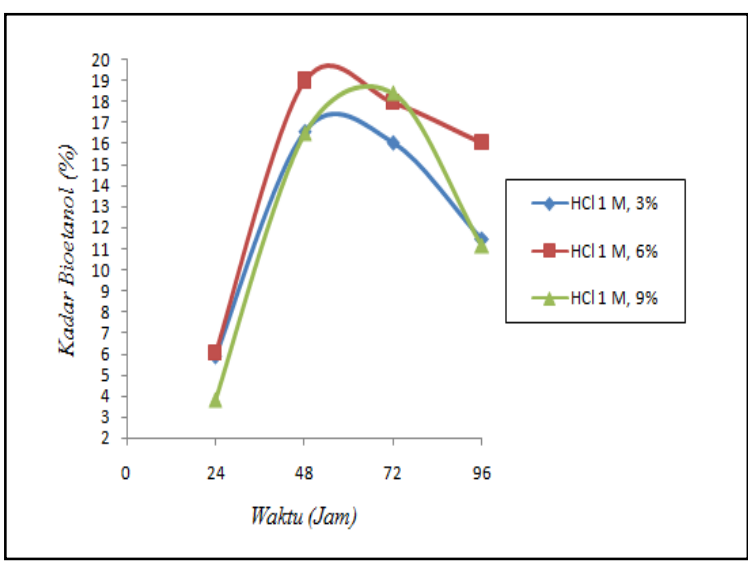

Gambar 3. Pengaruh Massa Ragi dan Waktu Fermentasi Terhadap Kadar Bioetanol

Dari gambar 3 terlihat bahwa kadar bioetanol yang paling tinggi dihasilkan pada waktu 48 jam dengan massa ragi $6 \%$ yaitu $18,9998 \%$. Dari grafik diatas dapat diketahui semakin lama waktu fermentasi, kadar bioetanol akan semakin meningkat sampai batas waktu tertentu dan kemudian menurun. Hal ini berlaku juga untuk massa ragi 3\% dan $9 \%$. Hal ini sesuai dengan teori yang menyatakan bahwa waktu optimal untuk fermentasi alkohol adalah selama 48 jam [6].

Tetapi kadar glukosa yang dihasilkan masih terlalu kecil, hal ini juga disebabkan oleh distilasi yang masih sederhana untuk memisahkan distilat bioetanol serta kurang telitinya dalam menjaga suhu distilasi serta perlakuan saat proses fermentasi yang juga belum optimal.

\section{Pengaruh Massa Ragi Dan Waktu Fermentasi Terhadap Nilai Kalor Bioetanol}

Pada gambar 4 nilai kalor yang tertinggi pada waktu 48 jam dengan konsentrasi asam pada saat 
hidrolisis 1M yaitu sebesar 167,092 kkal/kg. Nilai kalor yang diperoleh pada bioetanol yang dihasilkan dari biji durian masih sangat kecil dibandingkan dari bioetanol dari bahan baku berbeda, diantaranya nilai kalor dari sampah organik berkisar antara $10.000-$ $11.000 \mathrm{kkal} / \mathrm{kg}$. Nilai kalor yang lebih besar akan menyebabkan lebih mudah terbakar sehingga kualitas bioetanol lebih baik [13]. Hal ini menunjukkan bahwa kualitas bioetanol yang dihasilkan pada penelitian ini masih sangat rendah.

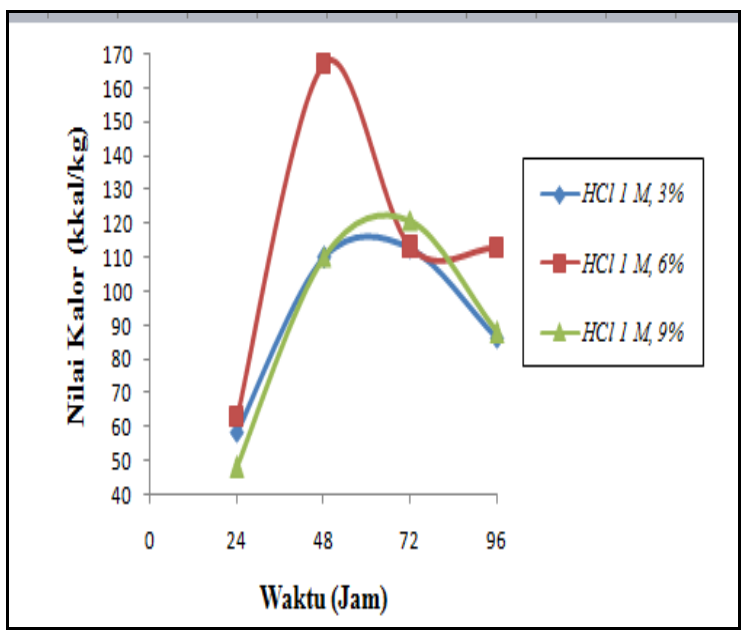

Gambar 4. Pengaruh Pengaruh Massa Ragi dan Waktu Fermentasi Terhadap Nilai Kalor Bioetanol

\section{Perbandingan Standar Baku Mutu Bioetanol}

Tabel 3. Syarat Mutu Bioetanol [3]

\begin{tabular}{|c|c|c|c|c|}
\hline Parameter & Satuan & $\begin{array}{c}\text { Mutu } \\
\text { Standar } \\
\text { Bioetanol }\end{array}$ & \begin{tabular}{|c|} 
Bioetanol \\
Biji \\
Durian \\
\end{tabular} & Ket. \\
\hline $\begin{array}{l}\text { Kadar } \\
\text { Etanol }\end{array}$ & $\% \mathrm{v} / \mathrm{v}$ & $\begin{array}{l}\text { Min. } \\
94,1\end{array}$ & 18,9998 & $\begin{array}{l}\text { Belum } \\
\text { sesuai }\end{array}$ \\
\hline $\begin{array}{c}\text { Minyak } \\
\text { Fusel }\end{array}$ & $\mathrm{mg} / \mathrm{L}$ & $\begin{array}{c}\text { Maks. } \\
15\end{array}$ & - & - \\
\hline Aldehid & $\mathrm{mg} / \mathrm{L}$ & $\begin{array}{c}\text { Maks. } \\
30\end{array}$ & - & - \\
\hline Metanol & $\mathrm{mg} / \mathrm{L}$ & $\begin{array}{c}\text { Maks. } \\
30\end{array}$ & - & - \\
\hline Densitas & $\mathrm{gr} / \mathrm{ml}$ & $\begin{array}{l}\text { Maks. } \\
0,8215\end{array}$ & 0,9669 & $\begin{array}{l}\text { Belum } \\
\text { sesuai }\end{array}$ \\
\hline $\begin{array}{c}\text { Spesific } \\
\text { Grafity }\end{array}$ & - & $\begin{array}{l}\text { Maks. } \\
0,8215\end{array}$ & 0,9669 & $\begin{array}{l}\text { Belum } \\
\text { sesuai }\end{array}$ \\
\hline $\begin{array}{l}\text { Nilai } \\
\text { Kalor }\end{array}$ & kkal/kg & $\begin{array}{c}\text { Maks. } \\
5000\end{array}$ & 167,092 & $\begin{array}{l}\text { Belum } \\
\text { sesuai }\end{array}$ \\
\hline $\begin{array}{l}\text { Keasaman } \\
\text { (sebagai } \\
\text { asam } \\
\text { asetat) }\end{array}$ & $\mathrm{mg} / \mathrm{L}$ & $\begin{array}{c}\text { Maks. } \\
30\end{array}$ & - & - \\
\hline Kadar Air & $\% \mathrm{~b} / \mathrm{b}$ & Maks. 2 & - & - \\
\hline
\end{tabular}

umum, dimana standar ini digunakan untuk menyatakan kelayakan bioetanol sebagai bahan bakar. Pada tabel 3 akan dilihat apakah bioetanol yang dihasilkan pada penelitian ini telah ditentukan sesuai dengan standar (sudah layak sebagai bahan bakar alternatif). Bioetanol yang dihasilkan pada penelitian ini memang belum sesuai dengan standar bioetanol yang telah ditentukan, hal ini disebabkan oleh beberapa faktor diantaranya:

1. Tidak adanya pemberian nutrient pada bakteri pengurai sehingga kurang bekerja secara optimal dalam mengubah glukosa menjadi bioetanol [7].

2. Tertimbunnya produk sehingga mempercepat kematian bakteri pada saat fermentasi berlangsung [5].

3. Kurang diperhatikan kemurnian dari ragi yang digunakan.

4. Proses pemurnian atau distilasi yang belum optimal (dibutuhkan distilasi bertingkat).

\section{Kesimpulan}

Kesimpulan dari penelitian ini adalah :

1. Jumlah bioetanol optimum yang diperoleh pada penelitian ini sebesar $3,7 \mathrm{ml}$ dengan densitas $0,9669 \mathrm{gr} / \mathrm{ml}$ dengan waktu 48 jam dan pemberian jumlah ragi $6 \%$.

2. Kadar bioetanol yang diperoleh sebesar $18,999 \%$ dengan waktu fermentasi 48 jam.

3. Nilai kalor optimum sebesar $167,092 \mathrm{kkal} / \mathrm{kg}$ dengan waktu fermentasi 48 jam dan pemberian jumlah ragi sebesar $6 \%$ dari jumlah bahan baku.

\section{Daftar Pustaka}

[1] AAK, Budidaya Tanaman Pad, Kanisus, Yogyakarta, 1990

[2] Astuty, E. D, Fermentasi Etanol Kulit Buah Pisang, Penerbit UGM, Yogyakarta ,1991.

[3] Badan Standar Nasional, Etanol Nabati, SNI 3565, Jakarta, 2009.

[4] Budiyanto, H.M, Mikrobiologi Terapan, Penerbit UMM Press, Malang, 2002.

[5] Dewati, Retno, Kinetika Reaksi Hidrolisa Kulit Durian Menjadi Glukosa Dengan Katalisator HCl Pada Tangki Berpengaduk, Penelitian Staf Pengajar Teknik Kimia: FTIUPNV, Jawa Timur, 2011.

[6] Gaur, Kadambini, Process Optimization For The Production of Ethanol Via Fermentation, Deemed Universty, Patiala, 2006.

[7] Manurung, Susyanti, Kombinasi Hidrolisa Asam dan Penggunaan Enzim dalam Fermentasi Alkohol dari Bungkil Kelapa Sawit, Penerbit Universitas Sumatera Utara, Medan , 2001 .

[8] Michael, Brown, "Durio a Bibliographic Review”, 1997. 
[9] Perry, R. H., D. W. Green and J.O.Maloney, Perry's Chemical Engineers Handbook, McGraw Hill Book Company $7^{\text {th }}$ Edition, New York, 1999.

[10] Prihandana, R., K. Noerwijati, P. G. Adinurani, D. Setyaningsih, S. Setiadi dan R. Hendroko, Bioetanol Ubi Kayu Bahan Bakar Masa Depan, Penerbit Agro Media Pustaka, Jakarta, 2008.

[11] Pusat Penelitian Sumberdaya Hayati dan Bioteknologi, Prosedur Pembuuatan Bioetanol, Laboratorium BIORIN Institut Pertanian Bogor, Bogor, 2010.

[12] Riadi, Lieke, Teknologi Fermentasi, Penerbit Graha Ilmu, Yogyakarta, 2007.

[13] Shuler, Michael L., and Fikret Kargi, Bioprocces Engineering, Prentille-Hall International editions, 1992.

[14] Sirait, Megawati, Pembuatan Etanol dari Ubi Kayu, Penerbit Universitas Sumatera Utara, Medan, 2005.

[15] Van Winkel, M., Distillation, McGrawHill. New York: 1967. 